\title{
A inclusão escolar de alunos com sequelas de mielomeningocele ${ }^{1}$
}

\author{
Caroline Penteado de Assis, Cláudia Maria Simóes Martinez
}

\begin{abstract}
Resumo: O objetivo deste estudo consistiu em identificar, analisar e discutir a utilização de recursos de Tecnologia Assistiva, em função das sequelas apresentadas pelos alunos com mielomeningocele incluídos no ensino regular. Participaram desta pesquisa 12 pessoas, sendo quatro alunos com sequelas de mielomeningocele e sete professores. Para coleta de dados, foram utilizados três instrumentos: a Escala de Percepção dos Professores sobre a Mielomeningocele, que tinha o objetivo de levantar o desempenho escolar dos alunos; o Roteiro de Observação do Desempenho do Aluno com Sequela de Mielomeningocele, utilizado para descrever o desempenho do aluno no contexto escolar, e por fim o Roteiro de Categorização do Uso da Tecnologia Assistiva no Contexto Escolar, que proporcionava a orientação da observação sobre o uso das tecnologias no contexto escolar. Os resultados indicaram que os únicos recursos encontrados para promover a participação dos alunos na escola foram duas cadeiras de rodas e uma órtese de posicionamento do tornozelo, recursos que o próprio aluno trazia para escola. Foi possível perceber que ainda há o desconhecimento por parte dos professores sobre as possibilidades concretas de implementação dos recursos de tecnologia, as quais estão relacionadas à falta de recursos, capacitação e identificação das reais necessidades e potencialidades dos alunos.
\end{abstract}

Palavras-chave: Escola, Mielomeningocele, Tecnologia Assistencial.

\section{School inclusion of students with myelomeningocele sequel}

\begin{abstract}
The aim of this study was to analyze and discuss the use of assistive technology, according to the myelomeningocele sequelae presented by students enrolledin the regular educational system. Twelve people participated in this research:fourschool students with myelomeningocele sequelae and seven teachers. Three instruments were used in order to collect data: "Scale of Teachers'Perception- Spina Bifida",which aims to raise the academic performance of students; "Roadmap Observation of Students'Performance"for students with myelomeningocele sequelae, which is used to describ estudents' performance in school context;and finally, "Road map Categorization of the Use of Assistive Technology", which provide saguidancenoteon the use of assistive technology at school. The results had indicated that the only joined resources to promote the participation of the students in the school they had been two chairs of wheels and one $\tilde{\mathrm{A}}^{3}$ rtese of positioning of ankle, resources that the proper pupil brought for school. It was possible to perceive that not yet it has the knowledge on the part of the teachers on the concrete possibilities of implementation of the technology resources, which they are related to the lack of resources, qualification and identification of the real necessities and potentialities of the students.
\end{abstract}

Keywords: Myelomeningocele, School, Assistive Technology.

\section{Introdução}

A mielomeningocele é uma doença que acomete o feto durante o processo de gestação por causa de uma má-formação congênita. A sua causa ainda é desconhecida, mas estudos sugerem uma etiologia multifatorial, sendo que os fatores citados são genéticos, ambientais e nutricionais, em mulheres com dieta pobre em ácido fólico, diabetes maternas, deficiência de zinco e ingestão de álcool ou drogas. (FERNANDES; ROCCO; SAITO, 2007).

Legalmente, a mielomeningocele é considerada uma deficiência física, mas a criança pode desenvolver, desde o nascimento, inúmeras sequelas. Dentre estas, 
existem os graus variáveis de paralisia, que estão relacionados à altura em que a lesão provocada pela má-formação do tubo neural se estabelece na coluna e que pode atingir as regiôes lombar, torácica e sacral, causando ausência de sensibilidade abaixo do nível da lesão medular, com preservação da parte superior do abdômen, tronco e braços. Além desse quadro, também podem surgir alteraçôes ortopédicas, como pés tortos congênitos e alteraçóes nos quadris e na coluna. A mielomeningocele também gera outras sequelas, como a hidrocefalia e a disfunção vesicointestinal. A hidrocefalia está presente em cerca de $90 \%$ dos casos e implica no crescimento rápido e anormal da cabeça, causada por complicaçóes quanto à forma de circulação e reabsorção do líquor. A interferência na circulação desse líquor gera um aumento da pressão intracraniana, que pode resultar em: retardo no desenvolvimento neuromotor; problemas visuais e auditivos; alteraçôes de fala; alterações cognitivas e da função nos membros superiores e inferiores. Já a disfunção vesicointestinal, também presente em cerca de $90 \%$ dos casos, é de origem neurológica; na medida em que o mecanismo de micção e esfincteriano não é automaticamente regulado, a criança apresenta incontinência. (FOBE et al., 1999; TAMBAQUIM et al., 2005; FERRARETO et al. 2006; ARAÚJO; GALVÃO, 2007; RAMOS et al., 2005).

Vale ressaltar que nenhuma sequela advinda da mielomeningocele ganha destaque pelo grau de comprometimento. Alimena, Machado Neto e Dirani (1999) discute que a interação entre a manifestação das sequelas e o nível de desenvolvimento (as possibilidades funcionais, de comunicação, interação social e de aprendizagem) vai ser determinante na Necessidade Especial que a pessoa com mielomeningocele apresentará. Assim, perfis distintos serão traçados, relacionados geralmente com a altura que a lesão se estabelece na coluna vertebral, pois as sequelas podem ou não se manifestar, ou até se intensificar, dependendo do grau de comprometimento.

Alguns estudos realizados por Bier et al. (1997), Yeates et al. (2003) e Guerra (2006) constataram que crianças com mielomeningocele e hidrocefalia têm uma maior propensão a desenvolver distúrbio de aprendizagem, porque existem dificuldades no processamento cognitivo relacionadas à atenção, o que proporciona um alto nível de distrabilidade e de déficit de memória, principalmente vinculado ao uso pobre de estratégias. Ainda, danos secundários, como alteraçóes visuais e auditivas advindas da hidrocefalia, podem prejudicar ainda mais o aprendizado.

Outro estudo realizado por Whitaker (2004) avaliou a influência da alteração motora no desempenho comunicativo de crianças com sequela de mielomeningocele. A autora constatou que a limitação causada pelo comprometimento físico interfere na forma da criança explorar o ambiente, brincar normalmente e se relacionar com outras crianças, e isso pode gerar um atraso no desenvolvimento neuropsicomotor da criança. Em função dessa série de comprometimentos apresentados, algumas crianças, segundo Salomão et al. (1995), têm uma maior suscetibilidade a síndromes de inadaptação social, em decorrência da manifestação das inúmeras sequelas apresentadas e do nível de desenvolvimento.

Atualmente, percebe-se que a expectativa de vida para crianças que nascem com mielomeningocele tem aumentado, principalmente em razáo do avanço dos estudos na área da reabilitação. Destaca-se que em épocas remotas tais crianças nem chegavam a se desenvolver, devido à complexidade das sequelas geradas em torno da doença. Assim, assiste-se a uma evoluçáo na área da saúde ao tratar pessoas com essa doença, o que tem favorecido um bom prognóstico. (BEHRMAN; KLIEGMAN; JENSON, 2002; HISABA et al., 2003; CUNHA et al., 2005).

Em consequência desse aumento na expectativa de vida e do movimento de inclusáo escolar, como um direito assegurado a todas as pessoas, independentemente de suas diferenças e necessidades, a partir da Constituição Federal de 1988 e da Lei de Diretrizes e Bases da Educaçáo Nacional/LDB 9394/96, crianças com mielomeningocele têm tido acesso ao contexto escolar. No entanto, diante das inúmeras sequelas que a criança pode desenvolver, desafios são vivenciados para sua inclusão no ensino regular, pois o perfil de necessidades especiais consequentemente vai interferir no processo de escolarização. Poucas pesquisas têm sido realizadas no Brasil para conhecer a realidade escolar dessas crianças.

Dentre os estudos publicados, encontraram-se três realizados no Rio de Janeiro, por meio do Instituto Fernandes Figueira da Fundação Oswaldo Cruz. O primeiro a ser descrito é de Macedo (2001), que teve como principal objetivo identificar qual o percentual de crianças com mielomeningocele cadastradas no Instituto Fernandes Figueira que tem acesso a escola pública e particular. A partir de entrevista realizada com 63 responsáveis pelas crianças com mielomeningocele, foi possível constatar que 90,47\% das crianças pesquisadas frequentavam regularmente a escola. Os dados da pesquisa revelaram que a maioria das matrículas escolares se fazia por absoluta persistência do usuário e não por incentivo do sistema. Muitas vezes, as mães precisavam permanecer ou ir frequentemente à escola para suprir 
as necessidades do aluno. Para a autora, a escola é uma das instituiçóes sociais que desempenham um papel fundamental no desenvolvimento cognitivo e social dessas crianças. No caso específico de crianças nascidas com mielomeningocele, pesquisas têm demonstrado que o acesso ao tratamento preventivo e adequado, e a outros serviços básicos essenciais, como a educação, pode modificar as histórias desses indivíduos, construindo a melhora da autoestima e os capacitando física, mental e socialmente para maior independência (MACEDO, 2001).

No outro estudo realizado, Chaves e Elias (2005) verificaram, junto a oitenta pessoas com sequelas de mielomeningocele, o conhecimento destas sobre o direito e a prática, em relação à matrícula em escola pública próxima da residência. A faixa etária dos participantes variou dos quatro aos dezesseis anos de idade, porém a maior porcentagem estava situada entre cinco e oito anos de idade. Aplicaram-se 153 entrevistas. Os resultados da pesquisa apontaram que as principais dificuldades foram o descrédito dos pais em relação ao ensino público; os problemas na acessibilidade das instalações; a má qualidade no atendimento, e o preconceito dos educadores. Para os autores, a deficiência física aparente dificultava a matrícula escolar, em função da falta de estrutura física adaptada nas escolas e de profissionais e professores treinados para alunos com sequelas de mielomeningocele. $\mathrm{O}$ estudo também constatou que as cuidadoras das crianças eram obrigadas a ficar nas salas de aulas acompanhando seus filhos, por exigência da escola, porque $90 \%$ das crianças com mielomeningocele sofriam de incontinência urinária e/ou fecal. Portanto, foi possível observar que a complexidade de sequelas desses alunos prejudicava sua inclusão na escola. Assim, uma dificuldade constantemente relatada foi a falta de medidas de promoção da acessibilidade, de forma sistemática.

E, por fim, a pesquisa realizada por Elias, Monteiro e Chaves (2008), que investigaram o processo de obtenção de três benefícios para pessoas com sequelas de mielomeningocele. Um destes foi o acesso à educação: os autores partiram do pressuposto de que a aceitação escolar ainda é um problema bastante comum e que afeta negativamente a socialização da criança, por causa do estigma da doença e do despreparo da rede educacional para incluir esses alunos. Participaram desse estudo oitenta indivíduos com sequelas de mielomeningocele, cujas famílias apresentavam renda per capita menor do que um quarto de salário mínimo e que haviam solicitado ou já tinham o benefício. Aplicaram-se entrevistas aos responsáveis pelos participantes. Os resultados da pesquisa apontaram para dificuldades relacionadas ao despreparo do sistema de ensino para receber crianças com necessidades especiais. Os autores ainda constataram que o fato de a criança com sequela de mielomeningocele estar matriculada na escola não garantia necessariamente a sua inserção escolar, embora fosse um passo importante para que esta se inicie. Outro problema detectado por meio da pesquisa foi a falta de acessibilidade física, considerada pelos autores um problema grave para esses alunos. As mães queixaram-se que nas escolas náo existiam rampas, banheiros ou mobiliário adaptados.

As pesquisas descritas apresentam as dificuldades no processo de escolarização desses alunos por meio dos relatos de seus responsáveis e revelam vários entraves para a escolarização de alunos com sequelas de mielomeningocele. Para aprofundar os estudos na área educacional com essa população, especificamente, torna-se necessário investigar diretamente a realidade desses alunos junto às escolas regulares, visto que eles vivenciam várias dificuldades no processo de escolarização em função do acometimento das sequelas oriundas da mielomeningocele. Dentre essas dificuldades, destaca-se a acessibilidade ao ambiente escolar. Uma das possibilidades apontadas para resolução desse problema tem sido o fornecimento de tecnologia especializada para amenizar a presença dessas diversidades (TEIXEIRA; LOURENÇO; MENDES, 2008).

Nesse sentido, alguns autores como Lauand (2005), Alves (2006), Bersh (2006, 2008) e Galvão Filho (2009) têm defendido o uso de Tecnologia Assistiva (TA) no contexto escolar a fim de ampliar as habilidades funcionais dos alunos com deficiência e maximizar seu desempenho. Assim, as tecnologias não auxiliam os alunos apenas na sala da aula, mas durante a rotina escolar para promover uma maior autonomia na escola. O objetivo da TA para educaçáo especial não é apenas trabalhar para resolver os problemas dos alunos e sim buscar instrumentos que o auxiliem a resolver suas próprias questóes.

Lauand (2005) discute sobre várias categorias de recursos de TA que podem ser utilizadas pelos alunos com necessidades educacionais especiais no contexto escolar. Dentre as quais, existem: os dispositivos acessórios computacionais especiais para viabilizar o acesso ao computador por alunos que tenham um comprometimento motor acentuado; recursos relacionados à mobilidade para favorecer a locomoção; elementos sensoriais para alunos que apresentam problemas visuais ou auditivos e até mesmo alteraçóes na fala, como recursos de comunicação alternativa; adaptaçóes para vida diária para realização das atividades de autocuidado; mobiliário adaptado 
para proporcionar um melhor posicionamento no contexto escolar; adaptaçóes pedagógicas recursos que promovem o acesso ao material de ensino para desenhar, escrever, recortar, colar, apagar e apontar, entre outras atividades escolares, e equipamentos adaptados para lazer e esporte, como brinquedos, jogos e equipamentos adaptados para realização das diferentes atividades pedagógicas.

Os decretos, as leis e políticas também preconizam a utilização de TA nos contextos educacionais. Dentre esses, o Decreto 3.298 de 20 de dezembro de 1999 (BRASIL, 1999) cita que as ajudas técnicas na escola são equipamentos e materiais pedagógicos especiais para a educação. Outro decreto, o de número 6.949, de 25 de agosto de 2009 (BRASIL, 2009), reforça a ideia da necessidade de utilização dos recursos de TA e responsabiliza os Estados por disponibilizá-los. A Política Nacional de Educação Especial na Perspectiva da Educação Inclusiva (BRASIL, 2008) instituiu que o atendimento educacional especializado deve ser constituído por um conjunto de recursos educacionais e de estratégias de apoio colocados à disposição dos alunos, proporcionando-lhes diferentes alternativas de atendimento, de acordo com as necessidades de cada um, para garantir que as especificidades dos alunos, não trabalhadas na classe comum, sejam amparadas.

Alguns autores pesquisaram sobre a utilização da TA no contexto escolar para alunos com deficiência física e comprovaram na prática a efetividade dos recursos dessa tecnologia. Dentre os estudos realizados, destacam-se o de Alpino (2008), que implementou um programa de consultoria colaborativa para alunos com deficiência física a partir de recursos de baixo custo destinados à adequaçáo postural e à mobilidade, e o estudo de Braccialli, Oliveira e Braccialli (2008), que verificou a influência da flexibilidade da superfície de assento da cadeira na velocidade e no tempo despendido por alunos com paralisia cerebral espástica no desempenho de atividades realizadas com os membros superiores. Tanto Alpino como Braccialli concluíram que os recursos favoreciam a independência e a autonomia dos participantes no contexto escolar.

No entanto, ainda constatam-se dificuldades para implementação dos recursos de TA nos contextos educacionais. Galvão Filho (2009), em um estudo de levantamento, descreveu a apropriação da Tecnologia Assistiva em quatro escolas estaduais da Bahia. Por meio dos resultados, o autor constatou nas escolas estudadas um estágio bastante inicial desse processo de apropriação e uso da Tecnologia Assistiva. Foram encontrados avanços e descobertas significativas, porém, ao mesmo tempo e majoritariamente, um profundo desconhecimento sobre as possibilidades concretas relacionadas a essa tecnologia, sobre os princípios da inclusão escolar ou mesmo sobre as reais potencialidades e necessidades dos alunos com deficiência.

Nota-se que vários aspectos foram descritos para justificar a realização deste estudo: o primeiro deles é que somente com avanços na área da saúde e a busca por direitos da pessoa com necessidade especial, pessoas com mielomeningocele têm tido acesso à escola regular. No entanto, a inclusão escolar desses alunos tem sido pesquisada apenas por meio de medidas indiretas, sem efetivamente investigar o seu cotidiano e a opiniáo dos profissionais na escola envolvidos nesse processo. Outra questáo importante discutida é que a utilização de TA é essencial para proporcionar a inclusão escolar de alunos com mielomeningocele, visto que inúmeras são as dificuldades vivenciadas por eles nesse processo, por causa das sequelas que podem se manifestar. Apesar disso, as pesquisas demonstram que, embora haja o incentivo para o uso da TA na escola, dificuldades ainda são evidenciadas para sua implementação no ensino regular. Diante desse cenário delineado, o objetivo desta pesquisa foi identificar, analisar e discutir, a utilização de recursos de Tecnologia Assistiva, em função das sequelas apresentadas por quatro alunos com mielomeningocele incluídos no ensino regular.

\section{Metodologia}

\subsection{Local}

Uma cidade de médio porte do interior do Estado de São Paulo, com uma população estimada em 200.000 habitantes. A escolha da cidade alvo da pesquisa ocorreu em função da política de inclusão desse município já ser amplamente utilizada pelos gestores de educação.

\subsection{Participantes}

Fizeram parte desta pesquisa doze participantes, sendo quatro alunos com sequelas de mielomeningocele e sete professores. Todos os alunos e respectivos professores participavam das escolas municipais. A idade dos alunos com sequelas de mielomeningocele variou de 5 a 8 anos e o gênero foi predominantemente masculino. As séries frequentadas por eles estenderam-se desde a Educação Infantil até o Ensino Fundamental. Os professores participantes da pesquisa foram 
predominantemente do gênero feminino, sendo que três professoras trabalhavam no atendimento educacional especializado e os outros quatro no ensino regular, e todos tinham formação para atuar como profissionais. Para garantir o sigilo dos participantes da pesquisa, eles foram identificados a partir de letras e números. Os alunos com sequelas de mielomeningocele foram representados por $\mathrm{C} 1$, $\mathrm{C} 2, \mathrm{C} 3$ e $\mathrm{C} 4$.

\subsection{Instrumento}

Foram utilizados três instrumentos específicos, construídos para este estudo: a Escala de Percepção dos Professores sobre a Mielomeningocele (EPP-MIELO), de medida indireta, cujo objetivo foi mensurar o desempenho escolar apresentado pelos alunos segundo a visão dos professores. Esse instrumento verificou oito áreas de desenvolvimento, elencadas a partir da revisão de literatura dos estudos de Fobe et al. (1999), Tambaquim et al. (2005), Ramos et al. (2005), Ferraretto et al. (2006), Araújo e Galvão (2007), e Fernandes, Rocco e Saito (2007). Assim, definiram-se quais as áreas de desenvolvimento que seriam utilizadas na EPP-MIELO: a comunicação; a cognição; a coordenação motora; a locomoção; a audição; a visão; o controle vesical e esfincteriano, e a interação social. O critério de pontuação foi baseado em uma escala, que utiliza sete pontos específicos: o número 1 indica a não presença da habilidade avaliada ou poucas possibilidades de desenvolvê-la; o número 2 representa que o aluno tem possibilidades para desenvolver a habilidade, mas ainda não consegue realizá-la; no número 3, o aluno apresenta a habilidade, mas não consegue utilizá-la a seu favor, e, por fim, os números 4, 5, 6 e 7 , que correspondem, sucessiva e respectivamente, a 25, 50, 75 e $100 \%$ da habilidade desenvolvida.

Aplicou-se a EPP-MIELO a oito professores, sendo cinco deles do ensino regular e três do atendimento educacional especializado, após a fase de teste. $\mathrm{O}$ tempo gasto para responder a escala variou entre $15 \mathrm{e}$ 20 minutos. $\mathrm{O}$ instrumento foi aplicado de maneira individual, na escola e em horário estabelecido pelos próprios professores. O pesquisador acompanhava o processo de preenchimento do instrumento para solucionar, de forma imediata, possíveis dúvidas que pudessem aparecer. A EPP-MIELO mostrou-se sensível para avaliar a visão que o professor tem sobre o desempenho escolar do aluno.

Outro instrumento presente na pesquisa foi o Roteiro de Observaçâo do Desempenho do Aluno com Sequela de Mielomeningocele. Este utilizou medida direta, na qual o próprio pesquisador mensurou as áreas de desenvolvimento que poderiam estar comprometidas nos participantes em razáo do acometimento da mielomeningocele. Estas foram elencadas por meio dos mesmos estudos utilizados para definir as categorias da EPP-MIELO. Assim, foram selecionadas: a locomoção, a comunicação e as atividades pedagógicas (cognição e coordenação motora), além de investigar também aspectos qualitativos, como: de que forma a criança realizava a atividade; qual a ajuda solicitava para sua realizaçáo; se apresentava dificuldades durante a execuçáo. Os critérios de pontuaçáo na escala eram os mesmo presentes na EPP-MIELO. Esse roteiro foi preenchido por meio da observação sistemática realizada em quatro escolas, das quais os alunos com sequela de mielomeningocele participavam. Para o preenchimento do roteiro, os observadores deveriam permanecer durante um período na escola.

O Roteiro de Categorização do Uso da Tecnologia Assistiva no Contexto Escolar, último instrumento construído, utilizou também medidas diretas, ou seja, a observação sistemática. Assim, tinha o objetivo de descrever e elencar quais as TAs utilizadas pelos alunos com sequelas de mielomeningocele no contexto escolar, por meio das diferentes categorias desenvolvidas por meio do estudo de Lauand (2005). Dentre estas, estavam presentes no instrumento: Dispositivos e Acessórios Computacionais Especiais recursos que permitem às pessoas com deficiência acesso ao computador; Mobilidade - recursos destinados para deslocamento e posicionamento das pessoas com deficiência; Elementos Sensoriais - recursos utilizados para atender a pessoas com deficiências sensoriais que permitem o acesso a diferentes formas comunicação; Adaptaçóes para Atividades de Vida Diária - recursos destinados para independência/autonomia pessoal que auxiliam as pessoas com deficiência nas tarefas de autocuidado, de higiene, alimentação e vestuário; Adaptaçôes Pedagógicas - recursos especializados para utilização na escola destinados para escrever, desenhar, substituir, manter ou ajustar partes do corpo faltantes ou comprometida; Elementos Arquitetônicos - recursos destinados a adaptaçôes estruturais no ambiente para promover acessibilidade; Mobiliário e Equipamentos Modificados - recursos feitos sob medida para proporcionar o acesso do deficiente à mobília necessário para realização de diferentes atividades, e Lazer/Recreação/Esportes - equipamentos adaptados que permitem à pessoa com deficiência o acesso à arte, às brincadeiras e às recreaçôes, e aos exercícios físicos. Em cada uma das categorias, existia a descriçáo de itens, como: nome do recurso, objetivo de sua implementação, ambientes da escola nos quais a 
criança utiliza o recurso, frequência de sua utilização, além dos espaços destinados para informaçôes complementares. O Roteiro de Observação foi aplicado em quatro escolas das quais os alunos com sequelas de mielomeningocele participavam. Para seu preenchimento, os observadores deveriam permanecer durante um período na escola, a fim de realizar as observaçóes do aluno com sequela de mielomeningocele em diferentes atividades escolares.

\subsection{Procedimento de coleta}

Primeiramente, o projeto foi encaminhado para o Comitê de Ética em Pesquisa em Seres Humanos da Universidade Federal de São Carlos (UFSCar) e obteve um parecer favorável ao desenvolvimento da pesquisa (protocolo CAAE 358/2008).

Assim, foi realizado o levantamento dos participantes da pesquisa; a pesquisadora entrou em contato com a Secretaria de Educação (rede municipal), a Diretoria de Ensino, (rede estadual), as Escolas Privadas e Especiais, para identificar as escolas dos alunos com mielomeningocele.

Optou-se por realizar a testagem de todos os instrumentos utilizados, pois estes foram elaborados para o presente estudo; portanto, ainda não haviam sido aplicados. Esse procedimento foi importante, para que se pudessem realizar as adequaçôes necessárias, a testagem de fidedignidade e a promoção da familiarização com os mesmos. Após esse procedimento, as escolas foram contatadas e os professores convidados a participar da pesquisa. Em seguida ao aceite, os professores do ensino regular e da sala de recursos responderam a EPP-MIELO em horários previamente estabelecidos por eles. Por fim, aplicaram-se o Roteiro de Observação do Desempenho do Aluno com Sequela de Mielomeningocele e o Roteiro de Caracterização do Uso da Tecnologia Assistiva. Para realização desse processo, o pesquisador permaneceu na escola durante um período que permitisse a observação do aluno em diferentes atividades escolares.

\section{Análise de dados}

A partir dos objetivos propostos pelo estudo, optou-se por estabelecer uma metodologia tipo descritiva exploratória. A análise de dados deste estudo foi realizada com base nos procedimentos quantitativos e qualitativos, pois se compreende que a relação paradigmática entre esses dados pode ser considerada complementar. No entanto, esta pesquisa utilizou predominantemente a abordagem qualitativa, em função do número de participantes encontrados (SILVA, 1998).

Para realizar a análise sobre o desempenho do aluno com sequela de mielomeningocele, utilizaram-se as notas de cada área de desenvolvimento da EPP-MIELO mensurada pelos professores e o Roteiro de Observaçáo do Desempenho do Aluno com Sequela de Mielomeningocele por meio das notas referente às áreas de desenvolvimento aferidas pelo pesquisador. Os dados desses instrumentos utilizados foram apresentados por meio de um único gráfico, o qual descreve o perfil de desempenho dos alunos nas diferentes áreas de desenvolvimento. Para obtençáo de uma nota única, realizou-se a pontuação média entre as notas aferidas pelos professores e pelo pesquisador.

Já no Roteiro de Caracterização do Uso da Tecnologia Assistiva, foi realizada uma análise qualitativa para cada um dos participantes da pesquisa por meio da descrição das categorias e dos recursos, bem como dos e graus de auxílio das TAs utilizadas no contexto escolar.

\section{Resultados e discussão}

\subsection{Perfil de desempenho apresentado pelos alunos com sequelas de mielomeningocele}

A Figura 1 descreveu todos os dados relacionados ao perfil dos participantes, no que se refere às áreas de desenvolvimento mensuradas dos quatro alunos com sequelas de mielomeningocele $\mathrm{C} 1, \mathrm{C} 2, \mathrm{C} 3$ e C4. Para traçar uma pontuação final, foi feita a média entre as pontuaçôes fornecidas pelo professor da sala regular, da sala de recursos multifuncional e do pesquisador.

A sequela de mielomeningocele presente em todos os participantes da pesquisa foi a falta de controle vesicoesfincteriano. A maioria dos participantes ganhou pontuação 1 na escala, que diz que a criança não apresentava tal habilidade e tinha poucas possibilidades de desenvolvê-la. Elias, Monteiro e Chaves (2008) discutem que o sistema urinário frequentemente está afetado, com disfunção miccional por bexiga neurogênica, acompanhada de incontinência urinária e, às vezes, fecal.

Para Macedo (2001), a incontinência é um dos principais motivos que dificultavam a matrícula e a permanência das crianças nas escolas. A mesma autora discute que a criança pode ter mais independência, se ela própria for capaz de fazer a troca de fraldas. 


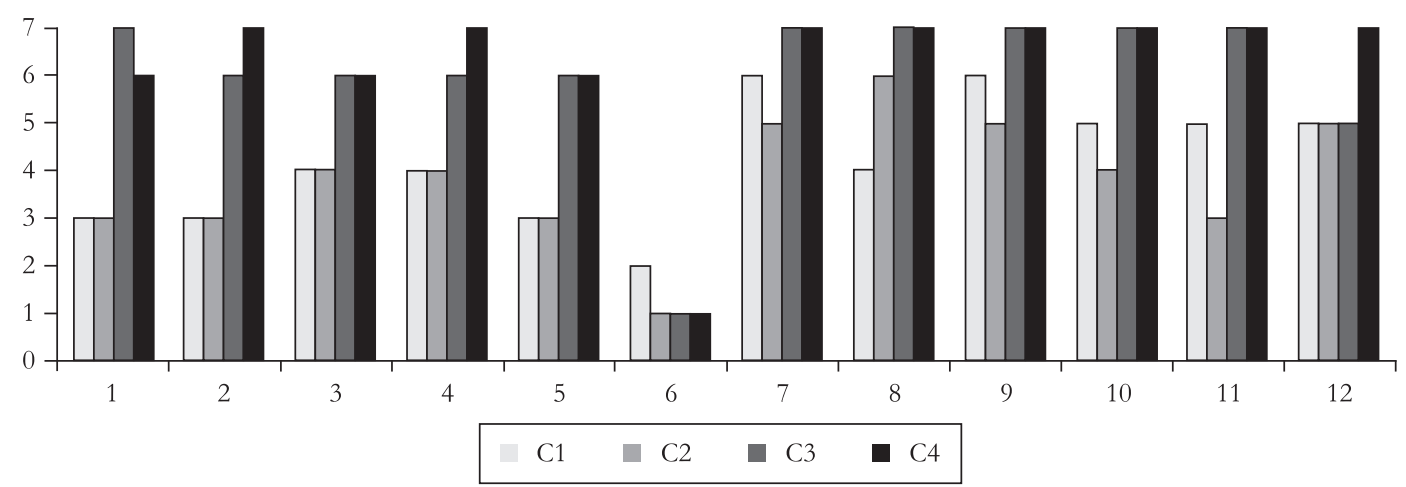

Figura 1. Perfil do desempenho escolar apresentado pelos participantes da pesquisa. Áreas de desenvolvimento avaliadas (eixo x): 1) Comunicação; 2) Coordenação motora fina; 3) Coordenação motora global; 4) Compreensão de ordem simples; 5) Compreensão de ordem complexa; 6) Controle vesicoesfincteriano; 7) Audição; 8) Visão; 9) Interação com os amigos; 10) Interação com o professor; 11) Interação com os funcionários da escola; 12) Locomoção.

Entretanto, essa ação só é válida para crianças que não apresentam comprometimento motor acentuado.

Alternativas foram adotadas para troca de fralda nas escolas participantes da pesquisa. Durante todo o horário escolar, a criança permanecia com a mesma fralda, evitando assim os problemas de troca. No entanto, essa é uma prática que compromete a higienização do aluno, que frequentemente sofre de infecção urinária, processo decorrente das sequelas causadas pela mielomeningocele.

Outra possibilidade utilizada era a ajuda da mãe, da avó ou do responsável, que ficava disponível na escola ou para ser chamada em casa, caso fosse necessário efetuar a troca de fraldas. Esta é uma das alternativas mais comuns para resolver os problemas de incontinência, mas nem sempre é psicologicamente aceita em crianças maiores. No caso dos participantes da pesquisa, a maioria náo permitia que a troca de fraldas fosse realizada pela professora, pois eles tinham vergonha da situação. Vale ressaltar que a fralda não é considerada um recurso de tecnologia assistiva, mas sim uma forma de lidar com a incontinência urinária.

Os dados do estudo de Chaves e Elias (2005) se assemelham à situação encontrada nesta pesquisa, pois $90 \%$ dos alunos entrevistados sofriam de incontinência urinária e/ou fecal, o que prejudicava ainda mais a aceitação deles na escola, se tornando mais uma fonte de estresse e insegurança para as crianças e suas famílias. Segundo a fala das mães participantes deste estudo, elas permaneciam todo o tempo na escola para ajudar e trocar as fraldas da criança.

Quanto à coordenação motora global, outra sequela importante identificada por meio dos dados, ela esteve relacionada à altura da lesão encontrada entre os participantes da pesquisa. Os alunos $\mathrm{C} 1$ e C2 apresentaram níveis torácicos de lesão; nesse caso, a pessoa não demonstra movimentação ativa nos membros inferiores e, em funçáo desse quadro, esses participantes eram cadeirantes. Os outros alunos tiveram pontuaçôes mais altas, como C3, que tinha lesão no nível lombar baixo, se locomovia por meio de rastejamento e tinha prognóstico de marcha. Para Elias, Monteiro e Chaves (2008), no nível lombar baixo, existem mais músculos dos membros inferiores náo comprometidos, como adutores; quadríceps; flexores mediais do joelho e, eventualmente, tibial anterior e/ou glúteo médio. Por fim, o último participante $\mathrm{C} 4$ possuía lesáo de nível sacral; a pessoa com esse nível de lesão apresenta os músculos supracitados funcionando e também possui função flexora plantar e/ou extensora do quadril, os quais favorecem o desenvolvimento da deambulação sem problemas na marcha (FERNANDES; ROCCO; SAITO, 2007).

No processo de escolarização, a restrição causada pelo comprometimento motor dificulta o desenvolvimento do aluno. Segundo Shepherd (1996), a incapacidade de se locomover pode gerar o atraso no desenvolvimento mental, físico e emocional. Whitaker (2004), na pesquisa realizada com crianças com sequelas de mielomeningocele, descreveu que $80 \%$ dos participantes necessitavam de cadeiras de rodas para se locomover e $20 \%$ apresentavam marcha autônoma. A autora discutiu que existe uma variabilidade dos achados neurológicos em relação ao nível da coluna vertebral. No seu estudo, a autora avaliou a influência da alteraçáo motora no desempenho comunicativo de crianças com sequela de mielomeningocele. Ela constatou que a limitação 
causada pelo comprometimento físico interfere na forma de a criança se comunicar, pois ela tem menores possibilidades de explorar o ambiente.

No que se diz respeito à comunicação, $\mathrm{C} 1$ e C2 foram pontuados com nota 4; portanto, apresentaram comprometimentos. Segundo Bier et al. (1997), Whitaker (2004) e Guerra (2006), pessoas com mielomeningocele têm déficits consideráveis na aquisição de linguagem não verbal. Bier et al. (1997) discutiu que o status socioeconômico da família da criança parece estar relacionado com o desenvolvimento verbal, enquanto que complicaçóes médicas relacionam-se com as habilidades não verbais. Isso significa que o desenvolvimento linguístico de crianças com sequelas de mielomeningocele depende não só das complicaçôes biológicas, mas também do contexto socioeconômico. Vale destacar, neste momento, que todos os participantes da pesquisa frequentavam escolas localizadas na periferia da cidade, pois eram perto de suas residências. Dessa forma, a dificuldade no desenvolvimento da linguagem pode ser não só decorrente das características biologicamente apresentadas pelos alunos, mas também de dificuldades presentes no contexto socioeconômico dos participantes.

Entre os participantes da pesquisa, C1 e C2 apresentaram maiores dificuldades de desenvolver interação social, porém não receberam pontuações que indicassem comprometimentos significativos. Ambos eram tímidos e não apresentavam iniciativa para comunicação com outras crianças. Em uma pesquisa realizada por Soares et al. (2006), os pesquisadores estudaram a sociabilidade de jovens com Espinha Bífida e constatou-se que existem dificuldades no desenvolvimento de interaçáo social. Os pesquisadores concluíram no seu estudo que o temor da diferença marca a dificuldade de aproximaçáo dos outros, reduzindo assim as oportunidades de interação entre os jovens deficientes e seus companheiros escolares, levando ao isolamento.

As professoras de $\mathrm{C} 2$ reclamaram da superproteção familiar que ele sofria; em função disso, ele apresentava várias dificuldades, dentre as quais a interação social. Para Soares et al. (2006), existem famílias que têm a tendência de superproteger os filhos; nesses casos, o que começa como preocupação e cuidado transforma-se em isolamento e infantilização. Whitaker (2004) discutiu que o desenvolvimento da linguagem pode ser prejudicado pela própria atitude dos familiares que, por excesso de zelo, interferem negativamente na integração da criança nos diferentes ambientes sociais e na motivação para a aprendizagem. Macedo (2001) discutiu que a superproteção tem um efeito negativo no processo de socialização da criança na escola, resultando no afastamento da criança do grupo de atividade e reforçando o processo de exclusão.

Assim, o problema enfrentado pelos alunos no desenvolvimento das interaçóes sociais pode ser influenciado por vários aspectos, como: as sequelas aparentemente visíveis que causam estranhamento no grupo social; o processo de superproteção familiar à criança, e também a própria restrição motora, que pode impedir a criança de iniciar espontaneamente as trocas sociais.

No estudo de Tambaquim et al. (2005), notou-se que o atraso do desenvolvimento mental, físico e emocional, por causa da incapacidade da criança de se locomover e explorar o seu ambiente, de brincar normalmente e se relacionar com outras crianças, constitui manifestações clínicas de caráter secundário da mielomeningocele, mas que estas também influenciam no desenvolvimento neuropsicomotor. Portanto, nota-se que a locomoçáo pode influenciar no desenvolvimento de outras habilidades, como o desenvolvimento da aprendizagem e a interação social.

Esse fato foi identificado na pesquisa por meio de dois alunos, C3 e C4. Esses participantes não apresentavam dificuldades de interação, visto que ambos tinham possibilidades de realizar a locomoçáo sem auxílio de recursos, dessa forma, as condiçōes biológicas dos alunos favoreciam a interação com os colegas e o ambiente escolar. Assim, eles possuíam uma atitude mais autônoma e independente que os outros participantes; apesar de também se irritarem com os comentários dos colegas, conseguiam desenvolver uma boa interação social.

Segundo Soares et al. (2006), a escola representa não apenas um espaço de aprendizado, mas também um ambiente importante para a interação social dos alunos, ou seja, um lugar onde são gerados e se solidificam vínculos de amizade. Para Macedo (2001), a escola desempenha um papel fundamental no desenvolvimento cognitivo e social da criança com sequela de mielomeningocele. Observa-se que, apesar de existirem dificuldades de uma inclusão escolar efetiva dos alunos com mielomeningocele, eles têm a oportunidade de vivenciar experiências que contribuem para o seu desenvolvimento, tendo maiores possibilidades de enfrentamento das adversidades e de serem resilientes ao contexto.

Quanto às funçóes cognitivas, os alunos com sequela de mielomeningocele $\mathrm{C} 1$ e $\mathrm{C} 2$ apresentaram lentidão no seu processamento, segundo a nota atribuída pelos professores, que foram, respectivamente, 3 e 3 . Tal fato pode estar associado à presença de hidrocefalia e mielomeningocele, 
mas é necessário lembrar que os professores não souberam informar sobre a utilização de válvula de drenagem. Foi observada pelo pesquisador a falta de concentração durante a realização das atividades em razão da alta distraibilidade, além das dificuldades de aprendizagem.

Segundo Fobe et al. (1999), crianças com hidrocefalia associada à presença de mielomeningocele frequentemente apresentam falhas no desenvolvimento das funçóes cognitivas; porém, é insuficientemente compreendido o papel das anormalidades neuropatológicas. Yeates (2003 apud TAMBAQUIM et al., 2005), estudando crianças com mielomeningocele, constatou que elas demonstram ter mais características de distúrbio de aprendizagem. A investigação dos fatores biológicos e sociais para a predição do desempenho cognitivo nessa população é muito importante para o planejamento de intervenções. Torna-se essencial destacar, nesse momento, que dificuldades relacionadas ao processamento cognitivo nos alunos participantes da pesquisa foram notadas pelos professores em séries mais avançadas. Durante a Educação Infantil, tais comprometimentos não foram percebidos pelo professor, apenas notados pelo observador.

No estudo realizado por Macedo (2001) sobre a escolarização de crianças com sequelas de mielomeningocele, $49,1 \%$ dos pais ou responsáveis relataram que seus filhos tinham dificuldades de aprendizagem relacionadas com leitura e matemática, e apresentavam alta distração e lentidão no processamento cognitivo. Em outra pesquisa realizada por Guerra (2006), constatou-se que crianças com sequelas de mielomeningocele associada à hidrocefalia apresentaram déficit cognitivo ligado geralmente à atenção, sendo este referente à alta distratibilidade e ao déficit de memória, ao reduzido domínio da língua e à deficiência de cálculo matemático. O teste de avaliação cognitiva detectou que as crianças com sequelas de mielomeningocele tiveram comprometimento principalmente no processamento de ordens complexas. Essa mesma realidade foi encontrada nos participantes $\mathrm{C} 1$ e $\mathrm{C} 2$, pois eles apresentaram dificuldades nessa mesma área de desenvolvimento.

Quanto às dificuldades de coordenação motora, os alunos $\mathrm{C} 1$ e $\mathrm{C} 2$ apresentaram problemas mais severos e obtiveram o desempenho 3 nessa habilidade. Para Macedo (2001), a maioria dos participantes do seu estudo possuía a coordenação motora prejudicada. Tambaquim et al. (2005) também constataram em pessoas com mielomeningocele prejuízos da organização motora e das funções manuais, decorrentes da baixa capacidade em dissociação de movimentos, ritmicidade, força e destreza. $\mathrm{O}$ desenvolvimento braquial estava afetado, o que dificultava a precisáo e o controle motor fino do movimento das mãos.

Shepherd (1996) discutiu que, em crianças com sequelas de mielomeningocele associada à hidrocefalia, o peso da cabeça faz com que elas demorem muito a firmá-la e o desenvolvimento geral da motricidade apresenta um atraso correspondente. Geralmente, a criança demora mais a se sentar e a manutenção do equilíbrio se instala tardiamente. Portanto, observa-se que esse atraso pode atingir também o período de escolarização dessas crianças, refletindo na realização das atividades escolares que requerem a utilização dos movimentos finos.

Existem estudos que correlacionam o atraso motor ao comprometimento cognitivo. Rendeli et al. (2002) constataram uma diferença estatisticamente significante entre os escores das escalas de avaliação cognitiva dos pacientes que andam (com ou sem ajuda) e dos pacientes que são dependentes de cadeira de rodas. Whitaker (2004) avaliou como a alteração motora ocasionada pelas sequelas de mielomeningocele influencia no desempenho comunicativo de crianças. Os dois autores concluíram que geralmente crianças com menor comprometimento motor têm um desempenho cognitivo melhor.

Tal fato também pode ser observado entre os participantes dessa pesquisa; $\mathrm{C} 1$ e $\mathrm{C} 2$, que apresentaram maior comprometimento motor, foram pontuados com pior desempenho nas habilidades cognitivas. Já C3 e C4, que apresentaram movimentação nos membros inferiores com possibilidades de locomoção, apesar de apresentarem comprometimentos de ordem cognitiva, mostraram possuir um desempenho melhor.

Uma das últimas habilidades comprometidas encontradas no participante $\mathrm{C} 1$ foi o problema na visão, detectado por meio da pontuação 4 . Ferraretto et al. (2006) realizaram uma pesquisa sobre achados oculares em pessoas com sequelas de mielomeningocele e identificaram que estas apresentam uma porcentagem de estrabismo maior do que o encontrado na populaçáo normal. A professora de $\mathrm{C} 1$ havia detectado a presença de problema visual e comunicado a família; entretanto, o aluno ainda náo tinha procurado o oftalmologista. Elias, Monteiro e Chaves (2008) constataram que a escassez de recursos das famílias para arcar com o transporte restringe a capacidade de buscar assistência médica, que, por ser especializada, raramente está disponível nos hospitais e postos de saúde próximos à residência. 
Nesta pesquisa, C1, C2, C3 e C4 foram encontrados nas escolas da periferia do município e, no caso citado, a família havia sido notificada que seu filho apresentava um problema, mas não tinha procurado atendimento médico. Segundo Elias, Monteiro e Chaves (2008), a falta de saúde reduz não só a capacidade da criança para frequentar a escola como também a sua capacidade de aprender.

\subsection{Caracterização do uso da Tecnologia Assistiva no contexto escolar}

Os dados descritos nesta seção dos resultados obtidos apresentaráo os recursos de tecnologia assistiva identificados no contexto escolar dos alunos com sequelas de mielomeningocele. As tabelas descreverão a categoria dos recursos de tecnologia assistiva, o próprio recurso e os graus de auxílio identificados pelo Professor da Sala de Recurso (SRr), pelo Professor da Sala Regular (SRg) e pelo Observador (Obs).

A Tabela 1 apresenta três recursos de Tecnologia Assistiva presentes no contexto escolar de C1: a cadeira de rodas, a mesa adaptada e a rampa. Pode-se observar que, dentre as oito categorias presentes no Protocolo de Categorização do Uso da Tecnologia Assistiva, apenas três foram encontradas: mobilidade e posicionamento; mobiliários e equipamentos modificados, e elementos arquitetônicos.

A cadeira de rodas foi o recurso encontrado, pertencente à própria criança, a qual a utiliza para sua locomoção na escola. C1 não conseguia ter independência total ao realizar sua locomoção em função da presença de barreiras e desnivelamentos arquitetônicos; geralmente, nesses locais, o aluno precisava ser auxiliado por outras pessoas para ter acessibilidade. $\mathrm{Na}$ escola de $\mathrm{C} 1$, existiam várias escadarias que davam acesso às diferentes salas, mas como a sua sala, o pátio e os refeitórios estavam localizados no térreo, o aluno não tinha problemas de deslocamento, se auxiliado pelo recurso.

$\mathrm{O}$ outro recurso referente ao posicionamento presente na escola de $\mathrm{C} 1$ foi uma mesa adaptada. Solicitou-se esse recurso à Secretaria de Educação para auxiliar a realização de atividades escolares; entretanto, não podia ser utilizado pelo aluno, pois possuía medidas inadequadas que impediam sua implementação. Um fato importante de se apontar é que o único recurso existente na escola não atendia as necessidades do aluno. Tal impasse ocorreu porque não foi feita a prescrição do recurso por um profissional especializado, fato que contribuiu para o abandono do recurso.

Existia também uma rampa de acesso na escola de $\mathrm{C} 1$; no entanto, esta não favorecia a locomoção independente desse aluno, pois sua inclinação náo era adequada, visto que o aluno precisa de ajuda para se locomover. Vale ressaltar que apenas o observador identificou a rampa como um recurso de TA.

A Tabela 2 descreve os recursos de Tecnologia Assistiva encontrados na escola de C2. Encontraram-se dois recursos: a cadeira de rodas e a rampa para promover acessibilidade do aluno ao ambiente escolar. Assim, as duas categorias presentes no instrumento foram mobilidade e posicionamento, e elementos arquitetônicos.

A cadeira de rodas de $\mathrm{C} 2$ o auxiliava efetivamente, possibilitando-lhe o acesso e a participação nos vários ambientes da escola. C2 conseguia se locomover com independência na maioria dos ambientes da escola, pois o piso era favorável e as portas eram largas. A presença dos desnivelamentos arquitetônicos foi observada somente no parque da escola e na rampa que dava acesso à entrada principal da escola.

Portanto, nota-se que esse elemento arquitetônico proporcionava acessibilidade ao contexto escolar, mas não favorecia o deslocamento independente

Tabela 1. Descrição dos recursos de Tecnologia Assistiva encontrados na escola de C1.

\begin{tabular}{cllcc}
\hline Categoria dos recursos de Tecnologia Assistiva & Recursos encontrados & \multicolumn{2}{c}{ Grau de auxílio } \\
\hline Recursos de mobilidade e & Cadeira de & SRg & SRr & Obs \\
posicionamento; & rodas & 5 & 7 & 6 \\
Mobiliário e equipamentos modificados & Mesa adaptada & 1 & 1 & 1 \\
Elementos arquitetônicos & Rampa & - & - & 2 \\
\hline
\end{tabular}

Tabela 2. Descrição dos recursos de Tecnologia Assistiva encontrados na escola de C2.

\begin{tabular}{cclcc}
\hline Categoria dos recursos de Tecnologia Assistiva & Recursos encontrados & \multicolumn{2}{c}{ Grau de auxílio } \\
\hline Recursos de mobilidade e & Cadeira de & SRg & SRr & Obs \\
posicionamento & rodas & 7 & 6 & 6 \\
Elementos arquitetônicos & Rampa & 7 & - & 2 \\
\hline
\end{tabular}


desse aluno por causa do seu grau de inclinação. Apenas o professor da sala regular e o observador identificaram a rampa como recursos de TA, sendo que o professor atribuiu pontuação máxima ao grau de auxílio proporcionado por ela.

A Tabela 3 apresenta a realidade de outra escola, a de C3, quanto aos recursos de Tecnologia Assistiva presentes. Encontraram-se dois recursos referentes à categoria de posicionamento e mobilidade, dentre os quais o carrinho 'estilo bebê' e a órtese de posicionamento do tornozelo.

O participante $\mathrm{C} 3$ também utilizava uma cadeira de rodas, mas era diferenciada, 'estilo carrinho de bebê'. Esta foi implementada pela solicitação da professora e emprestada pela Secretaria de Educação Especial, pois o aluno não tinha cadeira de rodas, uma vez que já realizava atendimento especializado para o treino de marcha. Visto que os professores náo conseguiam transportar a criança no colo, devido ao seu peso, a escola solicitou um meio de locomoção temporário para o aluno. Como medida emergencial, essa cadeira foi utilizada, mas ela não viabilizava a independência do aluno; era necessário o auxílio total da professora para se locomover.

Utilizava-se esse recurso quando era necessário se locomover até o parque, ir ao refeitório ou até a quadra. Mas vale ressaltar que quando C3 chegava aos locais era transferido ou para uma cadeira ou para o chão, e nesse ambiente geralmente a criança se locomovia por meio do rastejamento. $\mathrm{O}$ aluno até preferia se deslocar dessa forma, pois seus amigos verbalizavam que ele ainda era um bebê; portanto, ele tinha vergonha de utilizar o recurso, sendo alvo de preconceito dos colegas.

Segundo a visão dessa professora, esse recurso auxiliava consideravelmente o aluno na rotina escolar. Observa-se, nesse momento, que a falta de conhecimento específico sobre as possibilidades que a TA pode oferecer faz com que não se busquem alternativas que favoreçam uma maior independência e autonomia do aluno. Portanto, nota-se que parcerias entre profissionais da saúde e educação seriam fundamentais nesse processo.

Na pesquisa realizada por Macedo (2001), essa mesma cadeira de rodas 'estilo carrinho de bebê' era utilizada por um dos participantes do estudo.
Segundo os responsáveis pelos participantes, o seu uso dificultava para o aluno a visão do quadro-negro e a sua participação em atividades que utilizavam as mãos em razáo do mau posicionamento. No caso de C3, observou-se que diversos aspectos foram responsáveis para que o recurso de TA não fosse utilizado de forma funcional e, nesse caso, especificamente a cadeira de rodas 'estilo bebê' utilizada por C3: existiam vários empecilhos, como pouca motivação do usuário, falta de posicionamento adequado e ainda a vergonha do aluno ao utilizar o recurso. Para Galvão Filho (2009), a funcionalidade de um determinado dispositivo ou equipamento não é o único fator para o sucesso no uso de um recurso de TA; diversos outros aspectos são fundamentais, como fatores psicológicos e motivacionais, tendo de haver o interesse do usuário no processo ou no objetivo a ser alcançado com a TA. Devem ser considerados, dessa forma, os reflexos em sua autoimagem, se ele tem orgulho ou vergonha de utilizar o recurso, até fatores estéticos, sociais, ambientais, econômicos, etc.

Outro recurso encontrado foi a órtese utilizada por C3, identificada apenas pelo observador como TA, esta tinha o objetivo de posicionar as articulaçóes para favorecer a aquisição de marcha, prevenindo possíveis deformidades. No estudo realizado por Chaves e Elias (2005), com alunos com sequela de mielomeningocele, $73,7 \%$ das crianças faziam uso de órteses ou cadeira de rodas. Segundo os autores, tais recursos foram utilizados em função da deficiência física aparente, proporcionando a acessibilidade ao contexto escolar.

Vale ressaltar que o aluno C4 não apresentou comprometimento nos membros inferiores; portanto, não tinha a marcha comprometida e, dessa forma, participava do ambiente escolar sem utilizar recursos de tecnologia assistiva. Notou-se que quando o aluno com sequela de mielomeningocele não apresentava as sequelas físicas que prejudicassem a marcha, nenhum recurso de TA auxiliava o aluno no ambiente escolar.

É possível discutir que não estão sendo implementados recursos de tecnologia assistiva na escola. Encontraram-se, nos diferentes contextos escolares, cadeiras de rodas favorecendo a locomoção, pois, nos casos dos alunos $\mathrm{C} 1, \mathrm{C} 2$ e C3, os membros inferiores eram comprometidos inviabilizando a marcha sem auxílio. Portanto, sem esses recursos

Tabela 3. Descrição dos recursos de Tecnologia Assistiva encontrados na escola de C3.

\begin{tabular}{cllll}
\hline Categoria dos recursos de Tecnologia Assistiva & Recursos encontrados & \multicolumn{2}{c}{ Grau de auxílio } \\
\hline Recursos de mobilidade e & Carrinho 'estilo bebê' & SRg & SRr & Obs \\
posicionamento & Órtese de posicionamento & 7 & 6 & 5
\end{tabular}


que o próprio aluno trazia à escola, sua inserção no contexto escolar se tornaria inviável. Nos estudos de Macedo (2001) e Chaves e Elias (2005), a maioria dos participantes necessitavam do uso de cadeira de rodas para locomoção.

No que se refere às cadeiras de rodas de $\mathrm{C} 1$ e C2, estas estavam adequadas aos alunos, pois favoreciam um bom posicionamento e o deslocamento independente. Vale ressaltar que esses recursos foram implementados em um centro de reabilitação, ou seja, por profissionais da área da saúde. Já no caso de C3, como esse recurso foi implementado pela escola, sem nenhuma orientaçáo profissional, este não favorecia a locomoção independente desse aluno na escola.

Foi constatada a existência de rampas de acesso nas escolas; no entanto, a sua inclinação não permitia que os alunos pudessem se locomover com independência, necessitando sempre de auxílio. Galvão Filho (2009) aponta que, em vários estudos sobre fatores de sucesso na implementação de recursos de TA no contexto escolar, existe um frequente insucesso na participaçáo de todos os envolvidos no processo nas decisões sobre sua implementação.

Um dos únicos recursos diferenciados encontrados nas escolas foi a mesa adaptada, que foi solicitada à Secretaria de Educação, pois as medidas da cadeira de rodas de $\mathrm{C} 1$ eram incompatíveis com as medidas da carteira. Entretanto, como não houve prescrição do recurso por um profissional, a mesa adaptada não pôde ser utilizada, pois as suas medidas náo se adequavam às necessidades apresentadas pelo aluno; assim, o recurso foi abandonado. Questóes relacionadas ao abandono da TA são frequentemente descritas na literatura; Phillips e Zhao (1993), Scherer (1993) e Bell e Hinojosa (1995) discutem que a sua prescrição deve ser realizada por profissionais capacitados, que avaliem a situação biopsicossocial do aluno, orientem e capacitem o professor, além de acompanharem a implementaçáo dos recursos a fim de evitar que possíveis intercorrências resultem no abandono do recurso.

Nota-se que existem duas demandas diferenciadas de serviços que poderiam ser ofertados: uma é a adequaçáo dos recursos já existentes e a outra seria a implementação de vários outros recursos de TA, visto que existem comprometimentos identificados pelo professor e pelo pesquisador para os quais não existe nenhum recurso sendo utilizado.

A implementação de mobiliário adaptado seria essencial, pois existem três alunos cadeirantes e o posicionamento é fundamental para o processo de aprendizagem, uma vez que a postura é determinante para a concentraçáo e depende do alinhamento do corpo e sua estabilidade. Vale ressaltar que os alunos com mielomeningocele apresentam altos índices de distraibilidade como uma das sequelas de comprometimento cognitivo. As adaptaçóes pedagógicas poderiam potencializar a utilização das mãos em atividades que exijam a coordenação motora fina, como: engrossadores (lápis, caneta, canetinhas, cola e pincéis); tesoura adaptada; adaptação de réguas, e apontador de lápis. A maioria desses recursos é indicada para alunos com problemas na coordenação motora fina, a fim de lhes facilitar o manuseio desses objetos, o que no caso da pesquisa corresponde a comprometimentos identificados em $\mathrm{C} 1$ e C2. Para favorecer o processo de aprendizagem, o lúdico é bastante utilizado; assim, brinquedos adaptados podem favorecer o processo de atenção e interesse do aluno, proporcionando um melhor processamento cognitivo (MANZINI; SANTOS, 2002; EYER, 2003; RODRIGUES et al., 2008; BERSH, 2008).

Ainda nota-se que, nas escolas, a parceria com profissionais da área da saúde poderia favorecer a prescrição adequada da mesa adaptada e da cadeira de rodas no caso do aluno C3, evitando assim o abandono do recurso. No contexto atual da educação inclusiva, os professores se sentem 'órfãos' em uma proposta que necessita de parcerias e apoio. Galvão Filho (2009) coloca que os profissionais da educação percebem e vivenciam todas as mudanças ocorridas a partir da inclusão escolar, e sofrem, dentro da escola, as pressóes muitas vezes incongruentes e contraditórias dessas diferentes realidades, diante das práticas e dos modelos educacionais defasados, pedagogicamente inócuos e excludentes. Diante dessa situação, fica claro que não basta que o recurso de TA esteja disponível para a escola, pois é necessário que uma equipe habilitada avalie, oriente e implemente esses recursos (BERSH, 2006).

Notou-se, então, que os únicos recursos de TA que foram utilizados para promover a participaçáo do aluno no contexto escolar foram as cadeiras de rodas e a órtese, as quais foram implementadas por profissionais da área da saúde. Por meio dessas açôes, percebeu-se que vários profissionais foram importantes para que a utilização de TA fosse funcional. Para Pelosi (2008), conhecer a realidade escolar é fundamental tanto no que diz respeito a recursos tanto humanos quanto materiais, pois o professor intervém em um meio complexo, a escola, onde as exigências estáo cada vez maiores. Esse professor precisa de um repertório de ações para enfrentar as situaçóes individuais de 
aprendizagem dos alunos e as situaçóes do grupo, sendo a implementação da TA uma delas.

Segundo Galvão Filho (2009), para que se tenha sucesso na utilização da TA é necessário que todos os envolvidos - professores, familiares e usuários - contem com um suporte técnico em todas as etapas do processo, subsidiando os atores, em cada fase, com os conhecimentos necessários para as tomadas de decisão. A escola é um contexto importante para o desenvolvimento do aluno com necessidade educacional especial; portanto, deve utilizar os recursos que possam favorecer e viabilizar o aprendizado do aluno.

O suporte técnico que a escola deve dispor não pode restringir-se apenas às fases de implementação da TA, mas deve ir além, alcançando também as fases posteriores de acompanhamento, ajustes, personalização e revisóes. Para Pelosi (2008), a escola deverá contar com uma equipe de apoio ao professor, formada por vários profissionais, como: terapeutas ocupacionais; fonoaudiólogos; educadores; fisioterapeutas; psicólogos; engenheiros, e outros que poderão contribuir em todo trabalho de implementação do recurso de TA.

\section{Considerações finais}

Após discutir o perfil de desempenho escolar apresentado pelos participantes encontrados na pesquisa, torna-se fundamental dizer que, apesar das sequelas serem consideradas predominantemente físicas, várias outras podem ser consideradas secundárias, mas não menos importantes. A presença dessas sequelas advindas da mielomeningocele, ou seja, das características pessoais do aluno, pode influenciar a realizaçáo das atividades escolares de forma negativa. Portanto, nota-se que essas sequelas vão influenciar a interação do aluno no contexto, dificultando o seu desenvolvimento na escola.

A compreensão de todos esses aspectos é de fundamental importância para entender a inclusão escolar de alunos com sequelas de mielomeningocele. No entanto, vale ressaltar que a maioria dos professores teve dificuldades para reconhecê-las, na medida em que faltavam informaçóes sobre a patologia e, principalmente, o conhecimento de como as sequelas apresentadas pelo aluno interferiam no seu processo de inclusão escolar. Discute-se que as dificuldades na identificação principalmente das necessidades educacionais são um fator precursor de problemas no desenvolvimento escolar do aluno com sequelas de mielomeningocele, porque uma vez não identificadas as reais necessidades, os professores não realizam as adaptaçóes necessárias (como as de recursos, currículo e ambiente), a fim de proporcionar uma maior independência e autonomia do aluno no contexto escolar.

Foi possível perceber que ainda se vivencia nas escolas estudadas um estágio inicial do processo de utilização da Tecnologia Assistiva na inclusão escolar de alunos com sequelas de mielomeningocele, pois se permite apenas o acesso do aluno à escola e não às atividades escolares e ao currículo. Os princípios da inclusão escolar colocam em discussão na escola o atendimento das necessidades e capacidades dos alunos, proporcionando igualdade de oportunidades, mas os avanços ainda são muito difíceis e lentos.

Parte do desconhecimento sobre as possibilidades concretas de implementaçáo dos recursos de tecnologia está relacionada à falta de conhecimento sobre as reais necessidades e potencialidades dos alunos, além da falta de capacitação para reflexão sobre as possibilidades de implementação dos recursos.

Por meio dos resultados, foi possível observar que existem demandas para implementação dos recursos diante do desempenho escolar apresentado pelos alunos com sequelas de mielomeningocele, ou seja, existem possibilidades de promover e proporcionar um bom desenvolvimento escolar do aluno com sequela de mielomeningocele. No entanto, há dificuldades que devem ser compreendidas de forma sistêmica, a partir das muitas variáveis que interferem no desenvolvimento do problema da pesquisa. Apesar de existir um forte movimento para inclusão de pessoas com necessidades educacionais especiais no contexto escolar, apoiado por políticas de educação e decretos internacionais, ainda é evidente a falta de avanços nas transformaçóes das realidades tradicionais, como o acesso aos recursos, a disponibilidade de materiais e a falta de capacitação de recursos humanos.

Portanto, para implementação de recursos no contexto escolar, sugere-se que futuros estudos possam criar redes de apoio sob uma ótica interdisciplinar, para que a escola possa sentir-se assessorada nas questóes que envolvem a utilização de recursos de tecnologia assistiva. Nesse sentido, torna-se necessária a identificação das necessidades e capacidades do aluno, a fim de que se possa compreender sistemicamente a realidade escolar, para posteriormente propor açóes de intervenção.

Portanto, não basta que as políticas públicas preconizem a utilização de Tecnologia Assistiva no contexto educacional, pois é necessário que se criem formas eficazes para garantir a implementação de políticas públicas, a fim de que os alunos com sequelas de mielomeningocele tenham uma educação 
de qualidade, garantindo que seja realizado não somente o acesso, mas a permanência desse aluno no contexto escolar.

\section{Referências}

ALIMENA, L. J. M.; MACHADO NETO, L.; DIRANI, M. O perfil da mielomeningocele em um hospital pediátrico. Revista Brasileira de Ortopedia, v. 4, n. 34, p. 295-298, 1999.

ALPINO, A. M. S. Consultoria Colaborativa Escolar do Fisioterapeuta: acessibilidade e participação do aluno com paralisa cerebral em questão. 2008. 191 f. Tese (Doutorado em Educação Especial)-Universidade Federal de São Carlos, São Carlos, 2008.

ALVES, D. O. Sala de recursos multifuncionais: espaços para atendimento educacional especializado. Brasília: Ministério da Educação, Secretaria de Educaçáo Especial, 2006.

ARAÚJO, A. E.; GALVÃO, C. Desordens neuromotoras. In: CAVALCANTI, A.; GALVÃO, C. Terapia Ocupacional Fundamentaçāo Teórico Prática. Rio de Janeiro: Guanabara Koogan, 2007. p. 328-337.

BELL, P.; HINOJOSA, J. Perception of the impact of assistive devices on daily life of three individuals with quadriplegia. Assistive Technology, v. 7, n. 2, p. 87-94,1995. PMid:10159862. http://dx.doi.org/10 $.1080 / 10400435.1995 .10132257$

BEHRMAN, R. E.; KLIEGMAN, R. M.; JENSON, H. B. Defeitos do Tubo Neural. In: BEHRMAN, R. E.; KLIEGMAN, R. M.; JENSON, H. B. Tratado de Pediatria. 16. ed. Rio de Janeiro: Guanabara, 2002.

BERSH, R. Tecnologia Assistiva e Educação Inclusiva. In: BRASIL. Ministério da Educação - MEC. Secretaria de Educação Especial. Ensaios Pedagógicos. Brasília: MEC, 2006.

Bersh, R. Introdução ao Conceito de Tecnologia Assistiva. Porto Alegre: Centro Especializado em Desenvolvimento Infantil, 2008.

BIER, J.A.; MORALES, Y.; LIEBLING, J.; GEDDES, L.; KIM, E. Medical and social factors associated with cognitive outcome in individuals with myelomeningocele. Developmental Medicine \& Child Neurology, v. 39, p. 263-266, 1997.

BRACCIALLI, L. M. P.; OLIVEIRA, F. T.; BRACCIALLI, A. C. Influência do assento da cadeira adaptada na execução de uma tarefa de manuseio. Revista. Brasileira de Educaşão Especial, v. 14,n. 1, p. 141-154, 2008.

BRASIL. Decreto no 3.298, de 20 de dezembro de 1999. Política Nacional para Integração da Pessoa Portadora de Deficiência. Diário Oficial da República Federativa do Brasil, Brasília, DF, 21 dez. 1999. Disponível em: <http:// portal.mec.gov.br/seesp >. Acesso em: 27 fev. 2010.

BRASIL. Portaria Ministerial no 555, de 5 de junho de 2007. Política Nacional da Educação Especial na Perspectiva da Educaçáo Inclusiva. Prorrogada pela Portaria no 948, de 09 de outubro de 2007. Diário Oficial da República Federativa do Brasil, Brasília, DF, 2007.
BRASIL. Decreto no 6.571/08, 17 de setembro de 2008. Dispóe sobre o atendimento educacional especializado. Diário Oficial da Repúblçica Federativa do Brasil, Brasília, DF, 18 set. 2009. Disponível em: <http://portal.mec.gov. br/seesp>. Acesso em: 27 fev. 2010.

BRASIL. Decreto no 6949/09.25, de agosto de 2009. Promulga a Convenção Internacional sobre os Direitos das Pessoas com Deficiência e seu Protocolo Facultativo. Diário Oficial da Repúblçica Federativa do Brasil, Brasília, DF, 25 ago. 2009. Disponível em: <http://portal.mec. gov.br/seesp>. Acesso em: 27 set. 2009.

CHAVES, C. R. M.; ELIAS, M. P. Acesso à matrícula escolar para portadores de mielomeningocele. Revista da Academia Fluminense, n. 14, 2005.

CUNHA, C. J.; FONTANA, T.; GARCIAS, G. L.; MARTINO-ROTH, M. G. Fatores genéticos e ambientais associados a espinha bífida. Revista Brasileira de Ginecologia e Obstetricia, v. 27, n. 5, p. 268-274, 2005.

ELIAS, M. P.; MONTEIRO, L. M. C.; CHAVES, C. R. Acessibilidade a benefícios legais disponíveis no Rio de Janeiro para portadores de deficiência física. Revista Ciências em Saúde Coletiva, v. 13, n. 3, p. 1041-1050, 2008. http://dx.doi.org/10.1590/S1413-81232008000300027

EYER, R. M. A. Mobiliário Escolar Acessivel e Tecnologia Apropriada: Uma Contribuiçáo para o Ensino Inclusivo. Rio de Janeiro: Instituto Helena Antipoff, 2003. Oficina "Educação Inclusiva no Brasil - Diagnóstico Atual e Desafios para o Futuro".

FERNANDES, A. C.; ROCCO, F. M.; SAITO, E. T. Perfil dos pacientes com mielomeningocele da Associação de Assistência à Criança Deficiente (AACD) em São Paulo - SP, Brasil. Acta Fisiátrica, v. 14, n. 3, p. 130-133, 2007.

FERRARETTO, I.; COSTA, M. F.; AGUILAR, L. T.; TABUSE, M. K. U. T.; CRONEMBERGER, M. F. Achados Oculares em Pacientes com mielomeningocele. Arquivo Brasileiro de Oftamologia, v. 63, n. 5. p 379-382, 2006.

FOBE, J.-L.; RIZZO, A. M. P. P.; SILVA, I. M.; SILVA, S. P. M.; TEIXEIRA, C. E.; SOUZA, A. M. C.; FERNANDES, A. QI em pacientes com hidrocefalia e mielomeningocele: implicaçôes do tratamento cirúrgico. Arquivos de NeuroPsiquiatria, v. 57, n. 1. p 44-50, 1999.

GALVĂO FILHO, T. A. Tecnologia Assistiva para uma escola inclusiva apropriação, demanda e perspectiva. 2009.346 f. Tese (Doutorado em Educação)-Universidade Federal da Bahia, Bahia, 2009.

GUERRA, A. S. Funçôes cognitivas na hidrocefalia congenital associadas à mielomeningocele lombar na criança. 2006. 68 f. Dissertação (Mestrado em Neuropsiquiatria e Ciências do Comportamento)-Universidade Federal de Pernambuco, Recife, 2006.

HISABA, W. J.; MORON, A. F.; CAVALHEIRO, S.; SANTANA, R. M.; PASSOS, J. P.; CORDIOLI, E. Espinha bífida aberta: achados ultra-sonográficos e presença de contraçôes uterinas na predição da evolução motora neonatal. Revista. Brasileira de Ginecologia e Obstetricia, v. 25, n. 6, p. 425-430, 2003. http://dx.doi. org/10.1590/S0100-72032003000600007

LAUAND, G. B. A. Fontes de informação sobre tecnologia assistiva para favorecer à inclusão escolar de alunos com deficiências físicas e múltiplas. 2005. 224 f. Tese (Doutorado em Educação Especial)-Universidade Federal de São Carlos, Sáo Carlos, 2005. 
MACEDO, C. P. B. F. N. A Inclusão escolar de crianças com mielomeningocele: a inclusão como proposta. 2001. 120 p. Dissertação (Mestrado em Saúde da Criança)-Fundação Oswaldo Cruz, Rio de Janeiro, 2001.

MANZINI, E. J.; SANTOS, M. C. F. Banco de Idéias. In: BRASIL. Secretaria de Educação Especial. Portal de ajudas técnicas para educação. Equipamento e material pedagógico para educação, capacitação e recreação da pessoa com deficiência física: recursos pedagógicos adaptados. Brasília: MEC, SEESP, 2002.

PELOSI, M. B. Inclusão e Tecnologia Assistiva. Rio de Janeiro. 2008. 303.f. Tese (Doutorado em Educação)Universidade Federal do Rio de Janeiro, Rio de Janeiro, 2008.

PHILlIPS, B.; ZHAO, H. Predictors of assistive technology abandonment. Assistive Technology, v. 5, n. 1, p. 36-45, 1993. PMid:10171664. http://dx.doi.org/ 10.1080/10400435.1993.10132205

RAMOS, F. S.; MACEDO, L. K.; SCARLATO, A.; HERRERA, G. Fatores que influenciam prognóstico deambulatório nos diferentes níveis de lesão da mielomeningocele. Revista Neurociências, v. 13, n. 2, p. 80-87, 2005.

RENDELI, C.; SALVAGGIO, E.; CANNIZZARO, G. S.; BIANCHI, E.; CALDARELLI, M.; GUZZETTA, F. Does locomotion improve the cognitive profile of children with meningomyelocele? Child's Nervous System, v. 18, p. 231-234, 2002. PMid:12042922. http://dx.doi. org/10.1007/s00381-002-0557-4

RODRIGUES, M. M. C. et al. Sugestôes Para Escola APAE Bauru. In: INSTITUTO DE TECNOLOGIA DO BRASIL. Cartilha Tecnologia Assistiva nas Escolas: Recursos Básicos de Acessibilidade Sócio Digital para Pessoas com Deficiência. São Paulo, 2008.

SALOMÃO, J. F.; LEIBINGER, R. D.; CARVALHO, J. G. S.; PINHEIRO, J. A. B.; LUCCHESI, G. L.; BOMFIM, $\mathrm{V}$. Acompanhamento ambulatorial de pacientes com mielomeningocele em um hospital pediátrico. Arquivos de Neuropsiquiatria, v. 53, p. 444-50, 1995.
SCHERER, M. J. Viver no Estado de Preso:Como Technology Impacts a vida das pessoas com deficiência. Cambridge: BrooklineBooks,1993.

SILVA, R. C. A falsa Dicotomia Qualitativo-Quantitativo: Paradigmas que Informam nossas Praticas e Pesquisas. In: BIASOLI-ALVES, Z. M. M. Diálogos Metodológicos em Sobre Prática em Pesquisa. Riberão Preto: Legis Summa, 1998.

SHEPHERD, RB. Espinha Bífida. In: SHEPHERD, R. B. Fisioterapia em pediatria. 3.ed. São Paulo: Santos Livraria Editora, 1996:110-144.

SOARES, A. H. R.; MOREIRA, M. C. N.; MONTEIRO, L. M. C.; POHL, H. G. Qualidade de vida de jovens portadores de espinha bífida do Children's National Medical Center Washington DC. Revista Ciências em Saúde Coletiva, v. 11, n. 3, p. 817-826, 2006. http://dx.doi. org/10.1590/S1413-81232006000300029

TAMBAQUIM, D. L.; LAMÔNICA, D. A. C.; WHITAKER, M. E.; SENISE, C. Avaliação neuropsicológica e fonoaudiológica em crianças com mielomeningocele. In: Congresso Hispano-Português de Psicologia, 6., 2005, Lisboa. Anais... Lisboa, 2005.

TEIXEIRA, E.; LOURENÇO, G. F.; MENDES, E. G. Algumas consideraçôes para a escolarização de alunos com deficiência física no país: contribuiçōes da produção científica. In: Congresso Brasileiro de Educação Especial, 3., 2008, São Carlos. Anais... São Carlos: Universidade Federal de São Carlos. 2008. p. 10.

WHITAKER, M. E. Individuos com mielomeningocele: influência da alteração motora no desempenho comunicativo. 2004. Monografia (Especialização em Linguagem)-Faculdades de Odontologia de Bauru, Universidade de Sáo Paulo, Bauru, 2004.

YEATES, K. O.; LOSS, N.; COLVIN, A. N.; ENRILE, B. G. Do children with mielomeningocele and hydrocephalus display nonverbal learning disabilities? An empirical approach to classification. Journal of the International Neuropsychological Society, v. 9, p. 653-662, 2003. http:// dx.doi.org/10.1017/S1355617703940057

\section{Autores}

\section{Caroline Penteado de Assis}

Doutoranda do Programa de Pós-Graduação em Educação Especial, São Carlos, SP, Brasil

\section{Cláudia Maria Simóes Martinez}

Departamento de Terapia Ocupacional, Programas de Pós-Graduação em Educação Especial e em Terapia Ocupacional, Universidade Federal de São Carlos, São Carlos - UFSCar, SP, Brasil

\section{Colaboração dos Autores}

Os autores desse trabalho realizaram a descrição do artigo de forma conjunta, sendo que Cláudia Maria Simôes Martinez supervisionou sua elaboração com contribuiçốes substanciais para a confecção de sua estrutura e também por meio da análise interpretativa dos dados com revisão crítica do conteúdo descrito. Caroline Penteado de Assis atuou de forma a: realizar revisão bibliográfica sobre a escolarização de alunos com sequelas de mielomeningocele, descrever metodologicamente os procedimentos realizados, coletar os dados e os analisá-los interpretativamente articulando as discussóes apresentadas com a literatura científica.

\section{Notas}

${ }^{1}$ Parte dessas reflexões foi apresenta no V Congresso Multidisciplinar de Educação Especial, em Londrina-PR, 2009 e no IV Congresso Brasileiro de Educação Especial, em São Carlos-SP, 2010. 
